however, step in ; and my friend Leon Underwood, the sculptor, has propounded the first of the two views in his recently published "Bronzes of West Africa". But the archrologist will have the last word; and my own expectation, on the basis of such evidence as exists, is that, while the initial impulses of the Ife style will prove to have been carried, probably by the Yoruba themselves, from Nubia or thereabouts, excavation will establish that it was developed, and long flourished, in what is now south-western Nigeria.

Mr. Underwood has taken me mildly to task, in a review of this exhibition in Art News and Review (July 2), for suggesting in the catalogue of the exhibition that anthropology might help to import some valid objective standards into art criticism. But the art critic does not spurn the help of the laboratory expert who demonstrates that one painting is a forgery and another has been partly overpainted by a later hand, thus saving him from ridiculous discomfiture; he is in equal danger if, in considering primitive art, he ignores the guidance which anthropology can now, and will increasingly, give him. Facts, if properly established, are incontrovertible even by the most gifted of intuitive thinkers. Just as theologists have ceased to maintain, in the face of geology and archæology, that the world was created in 4004 B.C. (in return for the realization by men of science that they can neither prove nor disprove the existence of God), so artists and students of art should acknowledge that they cannot understand, or successfully learn from, primitive art without taking account of its ethnological aspects, and that the same may hold for civilized art at some time in the future, when the necessary techniques have been developed; but anthropologists and allied scientific workers must for their part realize that they cannot contract out of some of the most important and fruitful parts of their field, with the plea that they know nothing about art or have no ear for music, and still claim to be fully trained either in social anthropology or in material culture studies.

$$
46
$$

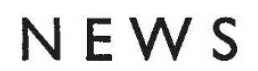

\title{
and VIEW S
}

Biochemistry at Guy's Hospital Medical School : THE appointment of P. G. A. D. Haslewood the newly established/caper olochemistry at Guy's Hospital Medical Schol marks a change in the organisation of he teaching of this subject at this Medical S mool The new Department of Biochemistry and Chpn try will combine the work formerly carried ouf in thl Department of Chemistry, under the diregtidio of Prof. C. S. Gibson, with the teaching and research in biochemistry, which until now has been a part of the work of the Department of Physiology. Dr. Haslewood received his early training at University College, London. After graduating, he worked with Prof. G. F. Marrian and others at University College during 1931-32 on the constitution of cestriol, as a result of which work they were able to propose a formula for this compound. During this time Dr. Haslewood also isolated a new steroid triol from pregnant mare's urine, and began his career as a teacher. In 1933 he joined the staff of the Research Institute of the Cancer Hospital, London. The preparation of methylcholanthrene from deaxycholic acid was there carried out by Prof. J. W. Cook and Dr. Haslewood. During 1935-39 he was on the staff of the Department of Pathological Chemistry at the British Postgraduate Medical School, where, with Prof. E. J. King and his staff, he worked out a number of microchemical methods for the analysis of blood samples. Throughout this time, he also carried on his work on the chemistry of the steroids, and succeeded in the partial synthesis of $3-\beta$-hydroxy- $\Delta^{5}$-cholenic acid. In addition, his isolation of 7-hydroxycholesterol from an ox liver extract re-opened the question of the oxidation of cholesterol under biological conditions, afterwards elaborated by Wintersteiner and others. In 1939 he was appointed reader in biochemistry at Guy's Hospital Medical School, since when, in addition to taking over the teaching of biochemistry at this Medical School, he has published papers on the metabolism of cholesterol and the bile acids, and on the excretion of "pregnanediol-like glucuronide" in human urine.
Preventive Medicine at Cardiff: Prof. F. Grundy

Dr. F. Grundy, medical officer of health to the Borough of Lyton, has been appointed professor of preventive medicine in the Welsh National School of Medicine Cardiff. Dr. Grundy, who is forty-three years of age, held a number of posts as medical officof and medical officer of health, until his appointment to Luton in 1937. All this time, he has shown a keen interest in social and preventive medicine, holding a number of public appointments in this connexion, such as the chairmanship of the British Social Hygiene Council-a position which he still holds. He has carried out important researches in social medicine and published a number of papers on certain aspects of it. Among his books may be mentioned his well-known "Handbook of Social Medicine" which is now recognized as a standard text. He has also travelled to various parts of the world, ineluding the Channel Islands, Sweden, Greece and the United States, for the purpose of studying and advising on health and hospital, maternity and other social services. In expanding its work in connexion with social and preventive medicine, it is doubtful if the Welsh National School could have made a better choice than Dr. Grundy to fill this new chair.

\section{Forestry and Forest Products in South-East Asia:}

\section{Dr. M. A. Hyberman}

Dr. M. A Huberman, technical officer in the Forestry Pranch, Forestry and Forest Products Division, Food and Agriculture Organisation of the United Nations, has gone to Bangkok, Thailand, hegdquarters of the Regional Office of the Organisation for Asia and the Far East, where he will act as chief of forestry and forest products. This post will be of great importance in that region in putting into effect recommendations of the forestry and timber utilization conference for Asia and the Pacific held by the Food and Agriculture Organisation in Mysore, India, during March 28-April 8. The importance of forestry is recognized as a prime factor in the raising of living standards throughout the world, and the Mysore conference, at which Dr. Huberman was 